\title{
Antioxidant and Cytoprotective Activities of Flavonoid Glycosides-rich Extract from the Leaves of Zanthoxylum bungeanum
}

\author{
Kai Zhong ${ }^{1}$, Xiao-Jie Li ${ }^{1}$, An-Na Gou ${ }^{1}$, Yi-Na Huang ${ }^{2, *}$, Qian Bu ${ }^{3}$, Hong Gao ${ }^{1, *}$ \\ ${ }^{1}$ College of Light Industry, Textile and Food Engineering, Sichuan University, Chengdu, China \\ ${ }^{2}$ Department of Public Health, Hua Xi Medicinal Center of Sichuan University, Chengdu, China \\ ${ }^{3}$ National Chengdu Center for Safety Evaluation of Drugs, West China Hospital, West China Medical School, Sichuan University, \\ Chengdu, China \\ *Corresponding author: dir0932@sina.com; gao523@hotmail.com
}

Received June 13, 2014; Revised June 24, 2014; Accepted July 02, 2014

\begin{abstract}
The Zanthoxylum bungeanum leaf has been traditionally taken as a vegetable and seasoning in China. To disclose the mechanisms of its benefit for human health, antioxidant activity and cytoprotective effect of the leaf were investigated. The ethyl acetate fraction exhibited the strongest ABTS and DPPH radicals scavenging activities as compared with chloroform and water fractions, as well as the crude extract. This fraction exhibited a protective effect against hydrogen peroxide-induced cytotoxicity in PC12 cells by MTT reduction assay. Furthermore, the cytoprotective effect was confirmed using flow cytometry analysis. Comparing with the model cells, the ethyl acetate fraction significantly increased G0/G1 and G2/M phase cells together with reducing S phase cells. Ten flavonoid glycosides were identified as isovitexin, vitexin, hyperoside, rutin, isoquercitrin, foeniculin, trifolin, quercitrin, astragalin, and afzelin from this fraction using high performance liquid chromatography-tandem mass spectrometry and nuclear magnetic resonance spectroscopy. This is the first report for the presence of vitexin, isovitexin, astragalin, trifolin and afzelin in $Z$. bungeanum. Hence, the results present here suggest the potential utility of $Z$. bungeanum leaf as a source of natural antioxidant due to its diversity and high content of flavonoids.
\end{abstract}

Keywords: Zanthoxylum bungeanum leaf, antioxidant, oxidative damage, cytoprotection, flavonoid glycoside

Cite This Article: Kai Zhong, Xiao-Jie Li, An-Na Gou, Yi-Na Huang, Qian Bu, and Hong Gao, “Antioxidant and Cytoprotective Activities of Flavonoid Glycosides-rich Extract from the Leaves of Zanthoxylum bungeanum." Journal of Food and Nutrition Research, vol. 2, no. 7 (2014): 349-356. doi: 10.12691/jfnr-2-7-4.

\section{Introduction}

Zanthoxylum bungeanum Maxim., commonly named Hua-Jiao in China, belongs to the Rutaceae family and has been widely used for its flavor and medicinal characteristics. The pericarps from the fruits of $Z$. bungeanum are good materials as a food spice in Chinese cuisine for its unique taste known as "ma" (a pungent taste). The leaf of $Z$. bungeanum is popularly consumed as a traditional vegetable and seasoning in Sichuan province of China. Z. bungeanum has also a wide application as a popular folk medicine for treatment of pathogenic wind, dampness, itch, abdominal pain, eczema, vomiting and diarrhea [1]. The plant species has been studied for its physiological activities, such as antifungal [2], antibacterial [3] and anti-inflammatory activity [4]. Recently, lifting properties of alkamide fraction from the fruit husks of $Z$. bungeanum have been reported [5]. In addition, some phytochemicals, such as essential oil [6,7], alkylamides [8], and flavonoids [9] have been identified from the fruits of $Z$. bungeanum.

Reactive oxygen species (ROS), such as hydrogen peroxide, superoxide anion, peroxyl radical and hydroxyl radical, can be generated as by-products of metabolic processes under oxidative stress. Elevated ROS levels have been implicated in many chronic diseases including Alzheimer's disease (AD), Parkinson's disease (PD), cancer, cataracts, atherosclerosis, cardiovascular diseases, and inflammation [10]. A previous study showed that antioxidants could prevent intracellular oxidative damage by scavenging free radicals generated in the oxidative chain reactions [11]. Therefore, there is a lot of interest in natural sources containing phenolic compounds as functional ingredients for disease prevention and health promotion. Flavonoid glycosides, typical phenolic compounds, are widely distributed in plants and play a significant role in plant biochemistry and physiology [12]. Additionally, they have been recognized to possess many bioactivities such as antioxidant, antiallergic, and hepatoprotective activities, as well as to be potent radical scavengers mostly due to their special chemical structure such as the position of hydroxyl groups, their polarity and aglycone moieties $[13,14]$.

Although it has been reported that nine flavonoid glycosides existed in the pericarps of $Z$. bungeanum grown in Hanyuan region, southwest of China [9], the phenolic compounds in the leaves of $Z$. bungeanum have 
been drawn less attention. Thus, the focus of this study is to evaluate the antioxidant ability and cytoprotective effect of phenolics-flavonoids enriched fraction obtained from the leaves of $Z$. bungeanum together with detecting its major compounds. The results will show the potential utility of the leaf of $Z$. bungeanum as a natural source of antioxidant against ROS.

\section{Materials and Methods}

\subsection{General Procedure}

Dulbecco's modified eagles medium (DMEM), trypsin, horse serum and fetal bovine serum were purchased from Hyclone Co. (USA). 2,2'-Azinobis-3-ethyl benzthiazoline-6-sulfonic acid (ABTS), 2,2-diphenyl1-(2,4,6-trinitrophenyl) hydrazyl (DPPH), penicillin, streptomycin, hyperoside, quercitrin, astragalin, rutin, gallic acid, potassium persulfate, Trolox, dimethyl sulfoxide (DMSO) and 3-(4,5-dimethylthiazol-2-yl)2,5-diphenyltetrazolium bromide (MTT) were purchased from Sigma-Aldrich Co.(St. Louis, MO, USA). Propidium iodide (PI) was obtained from BD Pharmingen (Franklin Lakes, NJ, USA). Triton X-100, RNAse A, HPLC grade methanol, HPLC grade formic acid, analysis grade chloroform, analysis grade ethyl acetate, hydrogen peroxide $\left(\mathrm{H}_{2} \mathrm{O}_{2}\right)$ and ferric sulfate were obtained from Zheng Chang Glass and Reagents Co., Ltd., Sichuan (China). The electron spray ionization-high resolution mass spectrum (ESI-HR-MS) was determined by time of flight mass spectrometry (TOF-MS, maXis impact, Bruker Daltonics, Bremen, Germany). MS parameters were set as follows: source type, ESI; ion polarity, positive; capillary, $3500 \mathrm{~V}$; end plate offset, $-500 \mathrm{~V}$; charging voltage, $2000 \mathrm{~V}$; nebulizer, 3.0 Bar; dry heater, $220^{\circ} \mathrm{C}$; dry gas, $6.0 \mathrm{~L} / \mathrm{min}$; $80-1200$ $\mathrm{m} / \mathrm{z}$. The nuclear magnetic resonance (NMR) spectra were recorded on a Bruker AV II-600 instrument $\left({ }^{1} \mathrm{H}, 600 \mathrm{MHz}\right.$; ${ }^{13} \mathrm{C}$, $\left.125 \mathrm{MHz}\right)$. 2-Dimensional NMR $\left({ }^{1} \mathrm{H}-{ }^{1} \mathrm{H}\right.$ COSY, HSQC and HMBC) spectra were obtained by using standard pulse sequences. Chemical shifts were recorded in DMSO- $d_{6}$ and presented in $\delta$ (parts per million) and the coupling constants $(J)$ in hertz.

\subsection{Extract Preparation}

The leaves of $Z$. bungeanum were collected in Hanyuan region, Ya'an city of Sichuan province, southwest of China, in July, 2011 and identified at the Department of Biology, Sichuan University. A voucher specimen was dried and preserved at the Key Laboratory of Food Science and Technology of Sichuan Province, Sichuan University, China.

Fresh leaves of $Z$. bungeanum were dried in the shade at room temperature. The dried leaves (200 g) were crushed into powders (60 granularity) and extracted with $1000 \mathrm{~mL}$ of $70 \%$ methanol by continuous stirring at room temperature for $24 \mathrm{~h}$. After centrifugation at $5000 \mathrm{rpm}$ for $10 \mathrm{~min}$, the supernatants were collected. After filtration, the filtrates were evaporated to dryness at $45{ }^{\circ} \mathrm{C}$ under vacuum and a total of $48.6 \mathrm{~g}$ crude extract was obtained. An amount of $38 \mathrm{~g}$ of the crude extract was suspended in $150 \mathrm{~mL}$ of distilled water and successively re-extracted with $n$-hexane (500 mL), chloroform (500 mL) and ethyl acetate $(500 \mathrm{~mL})$. The solvents were removed at reduce pressure to give $n$-hexane (0.125 g), chloroform (2.58 g), ethyl acetate (2.28 g) and water (33.02 g) fractions.

\subsection{Determination of Total Phenolics and Flavonoids Contents}

Total phenolics were determined using Folin-Ciocalteu method [15]. Analyses were performed by visible spectrophotometry at $750 \mathrm{~nm}$ after reaction with FolinCiocalteu's reagent. In brief, an amount of $0.1 \mathrm{~mL}$ of extract samples with different dilution was mixed with 2 $\mathrm{mL}$ of $\mathrm{Na}_{2} \mathrm{CO}_{3}(20 \mathrm{mg} / \mathrm{mL})$ for $2 \mathrm{~min}$, and then $0.9 \mathrm{~mL}$ of Folin-Ciocalteu's reagent (previously diluted 2-fold with distilled water) was added. The absorbance of reaction was measured at $750 \mathrm{~nm}$ by using the MAPADA V1100D spectrophotometer (Xinke Instruments Co., Ltd., Sichuan, China) after $30 \mathrm{~min}$ of incubation at room temperature. Total phenolics contents were calculated as gallic acid from a calibration curve: $y=0.8116 x-0.0018$, $R^{2}=0.999$, where $y$ was the absorbance and $x$ was the gallic acid equivalent (mg gallic acid/g extract).

Total flavonoids were determined by using a modified spectrophotometrical method [16]. To $0.1 \mathrm{~mL}$ of extract samples with different dilution, $2 \mathrm{~mL}$ of distilled water was mixed with $0.1 \mathrm{~mL}$ of $5 \% \mathrm{NaNO}_{2}$ for $6 \mathrm{~min}$, and then $0.2 \mathrm{~mL}$ of $10 \% \mathrm{AlCl}_{3}$ was added and mixed for $5 \mathrm{~min}$. The total volume was made up to $3 \mathrm{~mL}$ with distilled water. The absorbance of reaction was measured at $420 \mathrm{~nm}$ against a prepared blank by using the MAPADA V-1100D spectrophotometer. Total flavonoids contents were calculated as rutin from a calibration curve: $y=0.352 x-$ $0.0221, R^{2}=0.999$, where $y$ was the absorbance and $x$ was the rutin equivalent (mg rutin/g extract).

\subsection{ABTS Radical Scavenging Activity}

ABTS radical scavenging activity was determined according to a modified method [17]. In brief, $19 \mathrm{mg}$ of ABTS was reacted with $3.3 \mathrm{mg}$ of potassium persulfate overnight in the dark at room temperature. The working solution was prepared by diluting it with distilled water to get absorbance $0.70 \pm 0.02$ at $734 \mathrm{~nm}$. An amount of 30 $\mu \mathrm{L}$ of test sample was reacted with $2.97 \mathrm{~mL}$ of diluted ABTS and absorbance was recorded within 30 min at 734 $\mathrm{nm}$. The percentage scavenging activity was calculated by the following formula: ABTS radical scavenging activity $(\%)=\left(1-A_{1} / A_{0}\right) \times 100, A_{0}=$ absorbance of the control at $30 \mathrm{~min}, \mathrm{~A}_{1}=$ absorbance of the test sample at $30 \mathrm{~min}$. The activity was expressed as the concentration of sample necessary to give a $50 \%$ reduction in the original absorbance ( $\mathrm{IC}_{50}$ value). Trolox was used as a positive control. All samples were analyzed in triplicate.

\subsection{DPPH Radical Scavenging Activity}

DPPH radical scavenging activity was determined according to a previous report [17]. DPPH solution in methanol (0.1 mM) was prepared and used fresh for each test. An amount of $1 \mathrm{~mL}$ of test sample was reacted with 2 $\mathrm{mL}$ of $\mathrm{DPPH}$ solution and absorbance was recorded within $30 \mathrm{~min}$ at $517 \mathrm{~nm}$. The percentage scavenging activity was calculated by the following formula: DPPH radical scavenging activity $(\%)=\left(1-\mathrm{A}_{1} / \mathrm{A}_{0}\right) \times 100, \mathrm{~A}_{0}=$ absorbance of the control at $30 \mathrm{~min}, \mathrm{~A}_{1}=$ absorbance of 
the test sample at $30 \mathrm{~min}$. The activity was expressed as the concentration of sample necessary to give a $50 \%$ reduction in the original absorbance ( $\mathrm{IC}_{50}$ value). Ascorbic acid was used as a positive control. All samples were analyzed in triplicate.

\subsection{Cytoprotection Assay}

Rat pheochromocytoma (PC12) cells were obtained from the American Type Culture Collection (ATCC). Cells were propagated in DMEM with 10\% fetal bovine serum, 5\% heat-inactivated horse serum and antibiotics (100 U/mL penicillin, $100 \mathrm{mg} / \mathrm{mL}$ streptomycin) at $37{ }^{\circ} \mathrm{C}$ in a humidified atmosphere containing $5 \% \mathrm{CO}_{2}$.

MTT assay was determined according to the modified method [18]. Briefly, PC12 cells were plated into 96-well plates at the concentration of $5 \times 10^{4}$ cells $/ \mathrm{mL}$ using 100 $\mu \mathrm{L}$ of DMEM. After $24 \mathrm{~h}, \mathrm{PC} 12$ cells were pre-incubated with sample for $3 \mathrm{~h}$ before $1.0 \mathrm{mM} \mathrm{H}_{2} \mathrm{O}_{2}$ exposure for $1 \mathrm{~h}$. After treated with $\mathrm{H}_{2} \mathrm{O}_{2}$, cells were further incubated in $100 \mu \mathrm{L}$ of fresh medium with $20 \mu \mathrm{L}$ of MTT $(5 \mathrm{mg} / \mathrm{mL})$. After incubating for $4 \mathrm{~h}$, the supernatants were removed, and $150 \mu \mathrm{L}$ of DMSO was added to dissolve the formazan crystals. Finally, the purple solvent absorbance was determined at $490 \mathrm{~nm}$ using the Microplate Reader (BioRAD, USA).

Flow cytometric analysis was performed according to the method of Eckert et al. [19] with a slight modification. In brief, PC12 cells were plated in 6-well plates at a density of $4 \times 10^{4}$ in a volume of $2 \mathrm{~mL}$, and grown two days until they reached $80 \%$ confluence, and then treated with $0.4 \mathrm{mg} / \mathrm{mL}$ ethyl acetate fraction (hereafter defined as ZLE) for $3 \mathrm{~h}$ before $1.0 \mathrm{mM} \mathrm{H}_{2} \mathrm{O}_{2}$ exposure for $1 \mathrm{~h}$. After treatment, cells were collected and washed with icecold PBS and fixed with $70 \%$ ethanol. The fixed cells were harvested by centrifugation at $1000 \mathrm{~g}$ per min for 5 min and dissolved in $500 \mu \mathrm{L}$ of buffer containing $0.1 \%$ sodium citrate, $0.1 \%$ Triton X-100, RNAse A $(50 \mu \mathrm{g} / \mathrm{mL})$, and PI $(50 \mu \mathrm{g} / \mathrm{mL})$. Samples were stored at room temperature in the dark for $30 \mathrm{~min}$ at least, and then measured by flow cytometry (FACS Calibur, Becton Dicknson, USA).

\subsection{Chromatographic Separation}

A chromatographic column $(4.0 \times 30 \mathrm{~cm})$ filled with SBC MCI gel (50-70 $\mu \mathrm{m}$, Sci-Bio-Chem Co. Ltd., China) was used for fractionation of ZLE to purify components. Before using, pretreatment was necessary for activating gel, and the procedures were shown as follows: (1) The column of MCI gel was eluted with $500 \mathrm{~mL}$ of acetone; (2) An amount of $1000 \mathrm{~mL}$ of methanol was utilized for removing acetone; (3) The column was flowed by 2000 $\mathrm{mL}$ of deionised water at $4 \mathrm{~mL} / \mathrm{min}$ overnight. ZLE (4.82 g) was applied on the MCI column with a stepwise elution from water to methanol to give five fractions. The $35 \%$ aqueous methanol fraction (118.2 mg) was further purified by preparative HPLC [P270 series HPLC (Elite Analytical Instruments Co. Ltd., Dalian, China); column, Senshu Pak ODS-5251-SD $20 \times 250 \mathrm{~mm}$ i. d. with a particle size of 5 $\mu \mathrm{m}$ (Scientific Co., Ltd., Japan); mobile phase, watermethanol-formic acid = 75: $25: 0.1$; flow rate, $16 \mathrm{~mL} / \mathrm{min}$; $t_{\mathrm{R}}, 16.7 \mathrm{~min}$; detection, UV $254 \mathrm{~nm}$ ] to give compound $\mathbf{1}$ (7.9 mg) as yellow powders.
Compound 1: ESI-HR-MS (positive) $\mathrm{m} / \mathrm{z} 433.1115$ $[\mathrm{M}+\mathrm{H}]^{+}$(calculated for $\mathrm{C}_{21} \mathrm{H}_{21} \mathrm{O}_{10}, 433.1114$ ); ${ }^{1} \mathrm{H}-\mathrm{NMR} \delta$ (DMSO- $d_{6}$ ) ppm ( $J$ in Hz): 3.25-3.30 (3H, m, H-3", 4" and 5"), 3.51 (1H, m, H-6"), 3.74 (1H, m, H-6"), $3.83(1 \mathrm{H}$, d, $\left.J=8.8, \mathrm{H}-2^{\prime \prime}\right), 4.68$ (1H, d, $\left.J=12.8, \mathrm{H}-1 "\right), 6.25$ (1H, s, $\mathrm{H}-8), 6.75$ (1H, s, H-3), 6.88 (2H, d, $J=7.7, \mathrm{H}-3^{\prime}$ and 5'), 8.00 (2H, d, $J=7.7, \mathrm{H}-2$ ' and $\left.6^{\prime}\right), 13.14$ (1H, s, OH-5); ${ }^{13} \mathrm{C}-\mathrm{NMR} \delta$ (DMSO-d ${ }_{6}$ ) ppm: 61.79 (C-6"), 71.04 (C-4"), 71.35 (C-2"), 73.88 (C-1"), 79.16 (C-3"), 82.30 (C-5"), 96.68 (C-8), 102.90 (C-3), 104.43 (C-10), 105.11 (C-6), 116.29 (C-3' and 5'), 122.08 (C-1'), 129.41 (C-2' and 6'), 156.48 (C-5), 160.87 (C-9), 161.63 (C-7), 163.29 (C-4'), 163.37 (C-2), 182.37 (C-4).

\subsection{HPLC-MS Analysis}

The analytical column used for HPLC was an ODS-2 $\mathrm{C}_{18}(5 \mu \mathrm{m}, 4.6 \times 150 \mathrm{~mm}$, GL Sciences Inc., Japan $)$. The solvents used were water with $0.1 \%$ formic acid (A) and methanol with $0.1 \%$ formic acid (B). The elution gradient established was as the follow profile: $5-25 \%$ B from 0 to $10 \mathrm{~min}$; 25-30\% B from 10 to $20 \mathrm{~min}$; 30-35\% B from 20 to $30 \mathrm{~min}$; isocratic $35 \%$ B from 30 to $50 \mathrm{~min}$; $35-50 \%$ B from 50 to $60 \mathrm{~min}$; $50-60 \%$ B from 60 to $70 \mathrm{~min}$; $60-100 \%$ B from 70 to $80 \mathrm{~min}$; and isocratic $100 \%$ B for $10 \mathrm{~min}$. The flow rate was $0.5 \mathrm{~mL} / \mathrm{min}$ and the column temperature was maintained at $25{ }^{\circ} \mathrm{C}$. Online detection was performed in the diode array detection (DAD) with the wavelength range $200-700 \mathrm{~nm}$ and in a mass spectrometer connected to HPLC system.

The mass spectrometry system was an API 3200 Q-trap (Applied Biosystems, Darmstadt, Germany) equipped with an ESI source and a triple quadrupole-ion trap mass analyzer. The MS was performed as described in the literature [20]. Briefly, the quadrupoles were set at unit resolution. Parameter was set as follows: turbo ion spray probe, $400^{\circ} \mathrm{C}$; nitrogen pressure $30 \mathrm{psi}$; ion spray voltage, $4500 \mathrm{~V}$, negative mode; declustering potential, $450 \mathrm{~V}$; entrance potential, $6 \mathrm{~V}$; collision energy, $10 \mathrm{~V}$. MS spectra were recorded in negative ion mode between $\mathrm{m} / \mathrm{z} 100$ and 1000.

\subsection{Quantification}

The quantification of these phenolic compounds was performed using HPLC with external standard method while the column and analytical condition for HPLC was identical as described above. For quantification, commercially obtained hyperoside, rutin, quercitrin, astragalin, and isovitexin isolated from ZLE ( $>95 \%$ purity) were used as standard compounds. An amount of $10 \mu \mathrm{L}$ of each standard compound at different concentrations (i.e. 31.25, 62.5, 125, 250 and $500 \mu \mathrm{g} / \mathrm{mL}$ ) was prepared and subjected to HPLC separately. The calibration curve was obtained by plotting the concentration of the standard against the peak area. A best fit line that fitted the data points was made by linear regression method. A concentration of $20 \mathrm{mg} / \mathrm{mL}$ of the extract was prepared and $20 \mu \mathrm{L}$ volume was subjected to HPLC. The performed HPLC condition was identical as described above. The amount of the phenolic compounds in the extract was determined according to the peak area of the chromatogram of the extract with the calibration curve. 


\subsection{Statistic Analysis}

The data of all experiments were recorded as means \pm standard deviations of triplicate and analyzed with SPSS (version 17.0 for Windows, SPSS Inc.). The data were subjected to one-way analysis of variance (ANOVA), and significant differences between means were determined by the Student's $t$-test.

\section{Results and Discussion}

\subsection{Total Phenolics and Flavonoids Contents}

The total phenolics content in an extract often reflects its potential biological benefit, especially in evaluating its antioxidant ability. Therefore, we investigated the total phenolics and flavonoids contents of the extracts including chloroform fraction, ZLE, water fraction and 70\% methanol extract. As shown in Table 1, ZLE had the highest contents of total phenolics (614.74 mg gallic acid/g extract) and flavonoids (998.70 mg rutin/g extract), followed by the order of chloroform fraction, $70 \%$ methanol extract, and water fraction. The result suggests that flavonoids could be rich in the ethyl acetate fraction because of their similar polarity, which was consistent with the published literature [21].

\subsection{ABTS and DPPH Radicals Scavenging Assays}

The antioxidant capacity of each extract in vitro was examined by using ABTS and DPPH radicals scavenging assays. The results of these two assays were shown in Table 1. Each extract scavenged ABTS and DPPH radicals in a concentration-dependent manner (data not shown). The $\mathrm{IC}_{50}$ values of ZLE on ABTS and DPPH radical scavenging activities were 9.15 and $231.07 \mu \mathrm{g} / \mathrm{mL}$, respectively. ZLE exhibited the highest activities to scavenge ABTS and DPPH radicals among all tested extracts, even higher than that of positive controls (Table 1). The results indicated that contents of phenolics, especially flavonoids in the extract, had a positive correlation with its ABTS and DPPH radicals scavenging capacity. This finding was agreement with a previous report, which showed the same relationship between ABTS radical scavenging capacity and content of polyphenolics (including flavonoids) in grains [22]. Therefore, ZLE was used in subsequent experiments due to its excellent radical scavenging abilities.

Table 1. Total phenolics and flavonoids contents of each fraction obtained from $\mathrm{Z}$. bungeanum leaves and their ABTS and DPPH radicals scavenging activities

\begin{tabular}{|c|c|c|c|c|}
\hline \multirow[b]{2}{*}{ Sample } & \multirow{2}{*}{$\begin{array}{l}\text { Total Phenolics (mg gallic } \\
\text { acid/g extract) }\end{array}$} & \multirow{2}{*}{$\begin{array}{c}\text { Total Flavonoids (mg rutin/g } \\
\text { extract) }\end{array}$} & \multicolumn{2}{|c|}{$\mathrm{IC}_{50}(\mu \mathrm{g} / \mathrm{mL})$} \\
\hline & & & $\begin{array}{c}\text { ABTS radical } \\
\text { scavenging assay }\end{array}$ & $\begin{array}{c}\text { DPPH radical } \\
\text { scavenging assay }\end{array}$ \\
\hline $70 \% \mathrm{MeOH}$ extract & $218.18 \pm 15.44 a$ & $271.42 \pm 10.60 \mathrm{a}$ & $9.15 \pm 0.29 b$ & $231.07 \pm 4.65 b$ \\
\hline $\mathrm{CHCl}_{3}$ fraction & $224.76 \pm 13.74 a$ & $455.42 \pm 24.88 b$ & ND & $121.24 \pm 2.61 b$ \\
\hline ZLE & $614.74 \pm 7.59 b$ & $998.70 \pm 13.77 b$ & $2.30 \pm 0.17 a$ & $3.58 \pm 0.22 \mathrm{a}$ \\
\hline Water fraction & $149.44 \pm 8.82 a$ & $165.65 \pm 7.61 a$ & $17.11 \pm 0.48 b$ & $373.50 \pm 5.32 b$ \\
\hline Ascorbic acid & - & - & ND & $4.20 \pm 0.28 a$ \\
\hline Trolox & - & - & $2.80 \pm 0.13 a$ & ND \\
\hline
\end{tabular}

$70 \% \mathrm{MeOH}$ extract represents 70\% methanol extract from Z. bungeanum leaves; $\mathrm{CHCl}_{3}$ fraction represents chloroform extract from $70 \%$ MeOH extract; ZLE represents ethyl acetate extract from $70 \% \mathrm{MeOH}$ extract; Water fraction represents water extract from $70 \% \mathrm{MeOH}$ extract; ND = not detected. Values followed by the different letters indicated significant differences in the same column $(P<0.05)$.

Table 2. Retention times, UV-Vis, mass spectral data and quantification of flavonoid glycosides in the ethyl acetate fraction obtained from Zanthoxylum bungeanum leaves

\begin{tabular}{|c|c|c|c|c|c|c|}
\hline \multirow{2}{*}{ Compound } & \multirow{2}{*}{$t_{\mathrm{R}}(\min )$} & \multirow{2}{*}{$\lambda_{\max }(\mathrm{nm})$} & \multicolumn{2}{|c|}{ MS data } & \multirow{2}{*}{ Identification } & \multirow{2}{*}{ Contents } \\
\hline & & & MS $[\mathrm{M}-\mathrm{H}]^{-}$ & MS/MS & & \\
\hline 1 & 39.6 & 268,337 & 431.2 & $310.9,283.0$ & Isovitexin & $62.4 \pm 3.1$ \\
\hline 2 & 45.1 & 270,337 & 431.2 & $310.9,283.0$ & vitexin & $71.7 \pm 3.6$ \\
\hline 3 & 50.1 & 226, 256, 356 & 464.3 & $300.5,271.1$ & Hyperoside & $1070 \pm 35$ \\
\hline 4 & 52.1 & 214, 256, 356 & 609.1 & $301.5,271.2$ & Rutin & $456 \pm 16$ \\
\hline 5 & 52.1 & $220,256,354$ & 463.5 & $301.5,271.2$ & Isoquercitrin & $684 \pm 24$ \\
\hline 6 & 57.9 & 212, 256, 356 & 433.2 & $300.2,271.1$ & Foeniculin & $55 \pm 2.0$ \\
\hline 7 & 61.5 & $220,266,350$ & 447.0 & $284.4,255.0$ & Trifolin & $230 \pm 10$ \\
\hline 8 & 62.7 & $224,256,352$ & 447.1 & 301.5, 271.2, & Quercitrin & $255 \pm 15$ \\
\hline 9 & 63.4 & $218,264,350$ & 447.1 & 285.2 & Astragalin & $145 \pm 5.0$ \\
\hline 10 & 68.5 & $218,264,344$ & 431.3 & 285.3, 255.1 & Afzelin & $70.5 \pm 6.5$ \\
\hline
\end{tabular}

Flavonoid glycosides contents were expressed as micrograms per gram (mg/100 g) dry weight of Zanthoxylum bungeanum leaves.

\subsection{Cytoprotective Activity against $\mathrm{H}_{2} \mathrm{O}_{2-}$ induced Cytotoxicity in PC12 cells}

Oxidative stress becomes a detrimental condition when ROS is excess. ROS could damage biological molecules such as proteins, deoxynucleic acid, and lipid membranes, which cause apoptotic or necrotic cell death by disrupting cellular function and integrity [10]. This harmful oxidative stress has been considered as a major cause of cell injuries, which leads to many diseases such as AD, cancer, and cardiovascular diseases [23]. PC12 cells, a pheochromocytoma cell line derived from rat adrenal gland, have been exploited extensively as a model to study the cytoprotective effect of antioxidants [24]. $\mathrm{H}_{2} \mathrm{O}_{2}$ is also widely used as an inducer of oxidative stress in vitro models, which could lead to cell death [25]. In addition, it was reported that the cell damage effect induced by $\mathrm{H}_{2} \mathrm{O}_{2}$ could be attenuated by pretreating with antioxidants [24]. 
Therefore, the protective effect of ZLE on cell death induced by $\mathrm{H}_{2} \mathrm{O}_{2}$ was investigated by PC12 cell model.

Firstly, the effect of ZLE on PC12 cell viability was evaluated using an MTT assay. At growth doses of $100-400 \mu \mathrm{g} / \mathrm{mL}$, cell viabilities were in the range of $95-$ 99\% (data not shown). This result significantly indicated a non-cytotoxic property of ZLE on PC12 cells. Pretreated in ranges from 100 to $400 \mu \mathrm{g} / \mathrm{mL}$ ZLE for $3 \mathrm{~h}$ before exposure to $1.0 \mathrm{mM} \mathrm{H}_{2} \mathrm{O}_{2}$, the viability of PC12 cells was determined by MTT reduction assay. As shown in Figure 1, the viability of PC12 cells decreased to $76.4 \%$ only treated with $1.0 \mathrm{mM} \mathrm{H}_{2} \mathrm{O}_{2}$ for $1 \mathrm{~h}$. On the other hand, the viability of cells pretreated with different concentrations of ZLE for $3 \mathrm{~h}$ increased with different levels, and protective effect of ZLE was in a dose-dependent manner. When pretreated with $100 \mu \mathrm{g} / \mathrm{mL}$ ZLE, the viability of cells increased by $1.7 \%$ compared with that of cells only treated with $\mathrm{H}_{2} \mathrm{O}_{2}$. At the concentration of $400 \mu \mathrm{g} / \mathrm{mL}$, the viability of cells significantly increased by $15.7 \%$ compared with that of cells only treated with $\mathrm{H}_{2} \mathrm{O}_{2}$. This result demonstrated that PC12 cells damage induced by $\mathrm{H}_{2} \mathrm{O}_{2}$ was suppressed by pretreatment with ZLE.

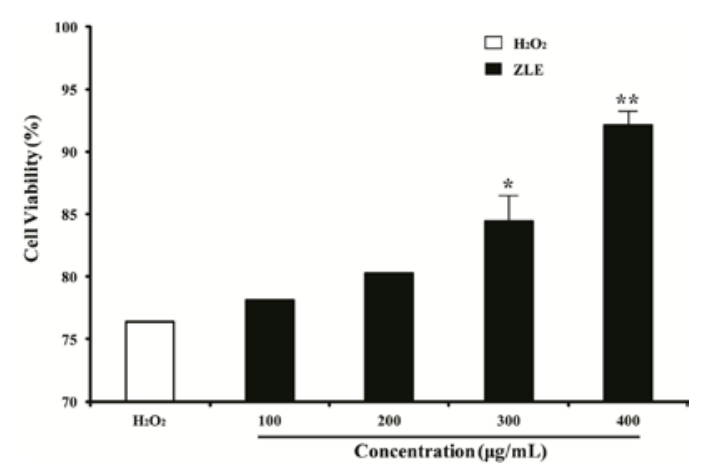

Figure 1. Protective effect of the ethyl acetate fraction obtained from Zanthoxylum bungeanum leaves on $\mathrm{H}_{2} \mathrm{O}_{2}$-induced cytotoxicity in PC12 cells. Pretreated with different concentration of the ethyl acetate fraction (ZLE) for $3 \mathrm{~h}$ before exposure to $1.0 \mathrm{mM} \mathrm{H}_{2} \mathrm{O}_{2}$ for $1 \mathrm{~h}$, the viability of PC12 cells were determined by MTT reduction assay. Data are presented as the mean $\pm \mathrm{SD}(n=3)$. ${ }^{*} P<0.05$ vs. $\mathrm{H}_{2} \mathrm{O}_{2}$ only, ${ }^{*} * P<0.01$ vs. $\mathrm{H}_{2} \mathrm{O}_{2}$ only

In order to confirm the protective effect of ZLE on PC12 cells damage induced by $\mathrm{H}_{2} \mathrm{O}_{2}$, flow cytometry analysis was adopted. Firstly, the cells were pretreated with ZLE at $400 \mu \mathrm{g} / \mathrm{mL}$ for $3 \mathrm{~h}$, followed by treatment with $1.0 \mathrm{mM} \mathrm{H} \mathrm{O}_{2}$ for $1 \mathrm{~h}$, and then the cell cycle was analyzed using flow cytometry. As shown in Figure 2A and Figure 2D, the PC12 cells without any treatments were revealed to express a consistent cell cycle phase distribution as follows: phase G0/G1, 57.68\%; phase G2/M, 8.07\%; phase S, 34.25\%. However, the cell cycle phase distribution significantly changed when cells were treated with $1.0 \mathrm{mM} \mathrm{H} \mathrm{H}_{2} \mathrm{O}_{2}$ for $1 \mathrm{~h}$, which were phase G0/G1, 44.24\%; phase G2/M, 0\%; phase S, 55.76\%; respectively (Figure $2 \mathrm{~B}$ and Figure 2D). The result suggested that the heteroploidy appeared and the apoptosis was happened in $\mathrm{H}_{2} \mathrm{O}_{2}$-treated model cells. Pretreated with $400 \mu \mathrm{g} / \mathrm{mL} \mathrm{ZLE}$ for $3 \mathrm{~h}$ before exposure to $1.0 \mathrm{mM} \mathrm{H}_{2} \mathrm{O}_{2}$ for $1 \mathrm{~h}$, cell cycle phase distribution became normal as that of cells without any treatments (Figure 2C and Figure 2D), and there was a significant increase in the proportion of cells in phases G2/M and G0/G1 with a corresponding decrease in the proportion of cells in phase $\mathrm{S}$. The result indicated that $\mathrm{H}_{2} \mathrm{O}_{2}$ as an oxidative inducer could cause cell damage at the G2/M phase of cell cycle, whereas cell damage caused by $\mathrm{H}_{2} \mathrm{O}_{2}$ significantly attenuated with pretreatment with ZLE. Recently, it has been reported that total flavonoids from Rosa Laevigata Michx attenuates $\mathrm{H}_{2} \mathrm{O}_{2}$-induced injury in human umbilical vein endothelial cells by decreasing $\mathrm{S}$ phase cells, suppressing nuclear morphological damage, inhibiting the collapse of mitochondrial membrane potentials, attenuating excessive ROS generation, reducing glutathione depletion, impacting the mitochondrial morphology change, decreasing caspase-3, -9 activities, and decreasing fragmented DNA [26]. Our finding is that ZLE can suppress PC12 cell death, resulting in protection against $\mathrm{H}_{2} \mathrm{O}_{2}$-induced oxidative damage in cells. However, it is still unknown whether ZLE or phenolic compounds in it could inhibit intracellular ROS, increase antioxidant enzymes, and restore the mitochondria. In order to disclose the detailed molecular mechanism of ZLE on protection against $\mathrm{H}_{2} \mathrm{O}_{2}$-induced cell oxidative damage, further study is currently being carried out in our laboratory.
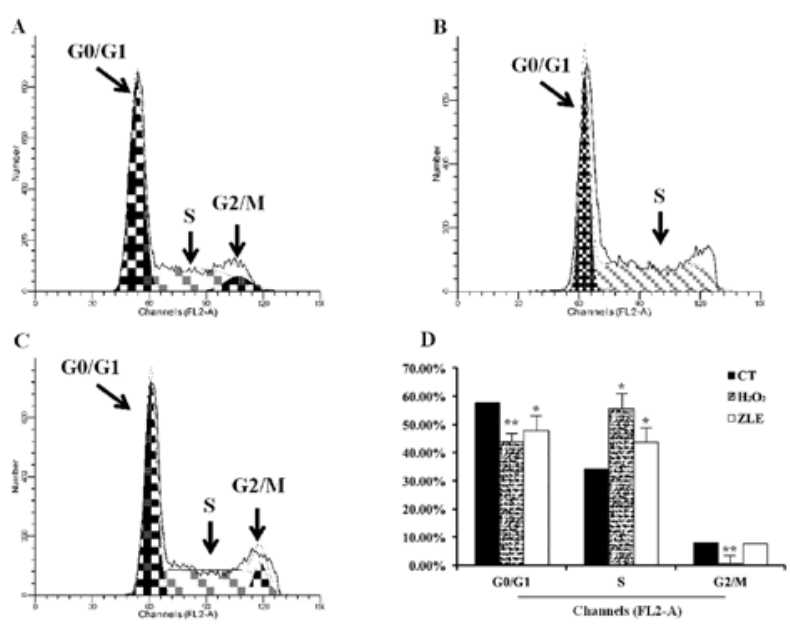

Figure 2. Flow cytometric analysis of cytoprotective effect of the ethyl acetate fraction obtained from Zanthoxylum bungeanum leaves on $\mathrm{H}_{2} \mathrm{O}_{2}$ induced cytotoxicity in PC12 cells. A: flow cytometric analysis of PC12 cells without any treatment (CT); B: flow cytometric analysis of PC12 cells exposured to $1.0 \mathrm{mM} \mathrm{H}_{2} \mathrm{O}_{2}$ for $1 \mathrm{~h}\left(\mathrm{H}_{2} \mathrm{O}_{2}\right)$; C: flow cytometric analysis of PC12 cells preincubated with $400 \mu \mathrm{g} / \mathrm{mL}$ ethyl acetate fraction (ZLE) obtained from Zanthoxylum bungeanum leaves for $3 \mathrm{~h}$ before exposured to $1.0 \mathrm{mM} \mathrm{H}_{2} \mathrm{O}_{2}$ for $1 \mathrm{~h}$; D: The proportions of cell cycle of these three different disposals of PC12 cells. ${ }^{*} P<0.05$ vs. CT only, ${ }^{* *} P<0.01$ vs. CT only

\subsection{Identification and Quantification}

ZLE was subjected to further analysis by NMR, HPLCDAD and HPLC-MS/MS due to its excellent antioxidant activity and high content of flavonoids among all tested fractions, and ten flavonoid glycosides (Figure 3) were identified. The major nine peaks were detected in ZLE by HPLC-DAD at $320 \mathrm{~nm}$ (Figure 4A). Peak 1 was purified by a SBC MCI gel column $(30 \times 4.0 \mathrm{~cm})$ and preparative HPLC. The ESI-HR-MS spectrum of compound $\mathbf{1}$ in positive mode gave a pseudomolecular ion peak at $\mathrm{m} / \mathrm{z}$ 433.1115 consistent with an elemental composition of $\mathrm{C}_{21} \mathrm{H}_{21} \mathrm{O}_{10}$ of the proposed molecular formula. In the ${ }^{1} \mathrm{H}$ NMR spectrum, signals due to $\delta_{\mathrm{H}} 6.25(1 \mathrm{H}, \mathrm{s}), 6.75(1 \mathrm{H}$, s), $6.88(2 \mathrm{H}, \mathrm{d}, J=7.7 \mathrm{~Hz}), 8.00(2 \mathrm{H}, \mathrm{d}, J=7.7 \mathrm{~Hz})$ suggested the characteristic pattern of flavone. The presence of 4'-stitution in B-ring was deduced from 
signals at $\delta_{\mathrm{H}} 6.88\left(2 \mathrm{H}, \mathrm{d}, J=7.7 \mathrm{~Hz}, \mathrm{H}-3^{\prime}\right.$ and $\left.5^{\prime}\right), 8.00$ $\left(2 \mathrm{H}, \mathrm{d}, J=7.7 \mathrm{~Hz}, \mathrm{H}-2^{\prime}\right.$ and $\left.6^{\prime}\right)$ in the ${ }^{1} \mathrm{H}-\mathrm{NMR}$ spectrum and at $\delta_{\mathrm{C}} 116.29$ (C-3' and 5') and 129.41 (C-2' and 6') in the ${ }^{13} \mathrm{C}$-NMR spectrum. Sugar carbon signals were observed at $\delta_{\mathrm{C}} 61.79,71.04,71.35,73.88,79.16$ and 82.30, indicating a characteristic of a glucopyranoside. An anomeric proton signal at $\delta_{\mathrm{H}} 4.68(1 \mathrm{H}, \mathrm{d}, J=12.8 \mathrm{~Hz}, \mathrm{H}-$ 1 ") suggested a $\beta$-glycoside linkage of sugar moiety. The structure of $6-C$-glycoside flavone was deduced from the HMBC between $\delta_{\mathrm{H}} 4.68$ and $\delta_{\mathrm{C}} 105.11$ (C-6), 156.48 (C-5) and 161.63 (C-7). Compound 1 was finally identified as isovitexin by comparing with these published data $[27,28]$.

Peaks 2-9 were identified according to retention times, their UV/Vis and mass spectra, and comparison with standards when available. Figure 4B showed the negative ESI-MS in full scan mode. ESI-MS and fragmentation data, retention time and spectrum information are displayed in Table 2.
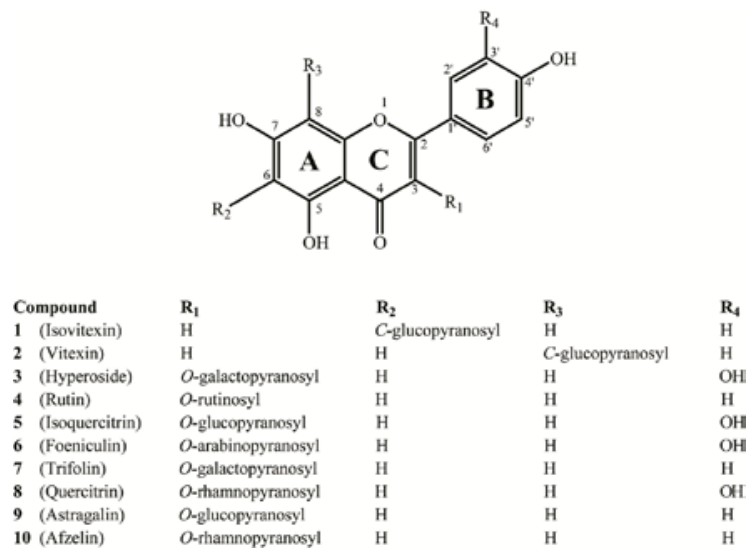

Figure 3. Chemical structures of the studied compounds 1-10 (1, isovitexin; 2, vitexin; 3, hyperoside; 4, rutin; 5, isoquercitrin; 6, foeniculin; 7, trifolin; 8, quercitrin; 9, astragalin; 10, afzelin) in the ethyl acetate fraction obtained from the leaves of Zanthoxylum bungeanum
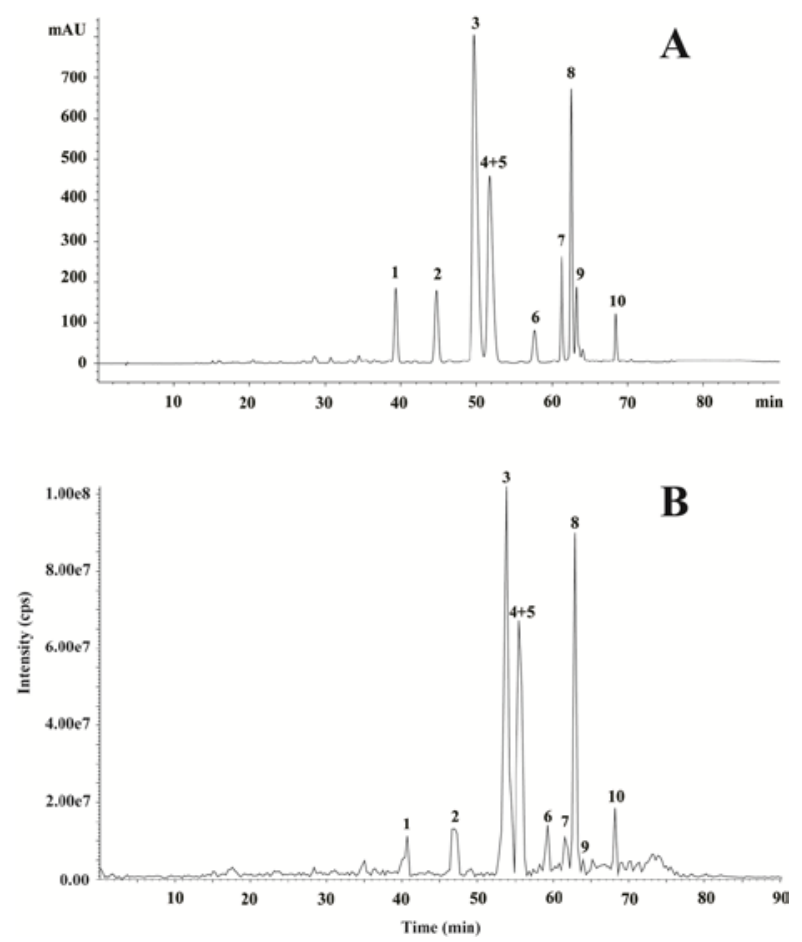

Figure 4. HPLC-DAD-MS chromatogram of the ethyl acetate fraction obtained from Zanthoxylum bungeanum leaves. A: Diode array detection (DAD) at $320 \mathrm{~nm}$. B: Negative ESI-MS in full scan mode
Compound 2 had the same molecular ion $[\mathrm{M}-\mathrm{H}]^{-}$at $m / \mathrm{z}$ 431.2 with compound 1 , as well as the same $\mathrm{MS}^{2}[\mathrm{M}-\mathrm{H}]^{-}$ fragments at $\mathrm{m} / \mathrm{z} 310.9$ and 283.0. This result indicated that compounds $\mathbf{1}$ and $\mathbf{2}$ are structural isomers. Compound 2 was finally identified as vitexin by comparison with its MS spectrum and MS/MS fragmentation patterns with that of the literature data [29].

The ion $[\mathrm{M}-\mathrm{H}]^{-}$of compound 3 was at $\mathrm{m} / \mathrm{z} 464.3(1 \mathrm{~m} / \mathrm{z}$ error) and its ion of MS/MS were at $\mathrm{m} / \mathrm{z} 300.5$ and 271.1, respectively. The above mentioned MS fragments data agreed with the published report [30]. Compared with HPLC retention time of authentic standard, compound $\mathbf{3}$ was identified as hyperoside.

Peak at 52.1 min in HPLC chromatogram (Figure 4A) showed two major molecular ions $[\mathrm{M}-\mathrm{H}]^{-}$at $\mathrm{m} / \mathrm{z} 463.5$ and 609.1 with high intensity, indicating that there are two compounds in it. Its $\mathrm{MS}^{2}[\mathrm{M}-\mathrm{H}]^{-}$gave ions at $\mathrm{m} / \mathrm{z} 301.5$ and 271.2, which suggested these two compounds were quercetin derivatives with sugar units. Therefore, compounds $\mathbf{4}$ and $\mathbf{5}$ were identified as rutin and isoquercitrin, respectively, by comparing with HPLC retention time of their authentic standards.

Compounds $\mathbf{6}$ and $\mathbf{8}$ showed ion molecular at $\mathrm{m} / \mathrm{z} 433.2$ ( $2 \mathrm{~m} / \mathrm{z}$ error) and 477.1, respectively. They almost gave the same MS/MS fragments at $m / z$ 301, revealing that they are quercetin derivatives with one sugar unit. It was previously reported that quercetin derivatives were the main flavonoids in $Z$. bungeanum fruits [9] and $Z$. bungeanum leaf, grown in Hubei [31]. Thus, we identified compounds $\mathbf{6}$ and $\mathbf{8}$ to be feoniculin and quercitrin, respectively.

Compounds 7 and 9 were identified as trifolin and astragalin by a loss of $162 \mathrm{Da}$, which indicated that lose of one hexose molecule, and both precursor ions scanned were at $\mathrm{m} / \mathrm{z} 285$ according to their MS/MS data. Discrimination between astragalin and trifolin can be based on the differences of their polarity [32] and HPLC retention time. Meanwhile, compound $\mathbf{9}$ was confirmed to be astragalin by comparing with its standard substance analyzed under the identical HPLC condition. Compound 10 was identified as afzelin by the pattern of HPLCMS/MS and comparing with the published data [9, 33].

The above result showed that the major flavonoids in ZLE were identified as isovitexin, vitexin, quercetin glycosides and kaempferol derivatives. It was similar to the finding of the previous study on the fruits of $Z$. bungeanum in Hanyuan, and quercetin derivatives, including compounds $3, \mathbf{4}, \mathbf{6}, \mathbf{8}$ and quercetin in the pericarps of Z. bungeanum [9]. However, compounds 1, 2, 5, 7, 9 and 10 were not detected in the fruits of $Z$. bungeanum.

The quantification of these flavonoids was performed by external standard method. The calibration curve was obtained by plotting the concentration of the standard against the peak area. The linear calibration curves of each standard compound were as the follow: compound $\mathbf{1}(y=$ $\left.1.11172 \times 10^{7} x-130455, R^{2}=0.999\right)$, compound $3(y=$ $\left.5884.8 x+1485.4, R^{2}=0.999\right)$, compound $4(y=3118.5 x$ $\left.+1585.1, R^{2}=0.999\right)$, compound $8(y=6453.5 x+4322.1$, $\left.R^{2}=0.998\right)$, compound $9\left(y=2699.8 \mathrm{x}+679.03, R^{2}=\right.$ 0.999). Since no standard was an available, compound $\mathbf{2 , 6}$, $\mathbf{7}$ and $\mathbf{1 0}$ were quantified with respect to compounds 1, 3, $\mathbf{9}$ and $\mathbf{9}$, respectively. Compounds $\mathbf{4}$ and $\mathbf{5}$ were quantified by calibration curve of compound $\mathbf{4}$, according to their 
ratio of ESI-MS intensity because of their same retention time, and the ratio was $1: 2$. Consequently, the amounts of these ten flavonoid glycosides were listed in Table 2. The order of amounts of these ten flavonoid glycosides was $\mathbf{3}>\mathbf{5}>\mathbf{4}>\mathbf{8}>\mathbf{7}>\mathbf{1}>\mathbf{9}>\mathbf{2}>\mathbf{1 0}>\mathbf{6}$.

The antioxidant activity of compounds $\mathbf{1}$ and $\mathbf{2}$ using DPPH, ABTS and ferric reducing assays has been well documented [27]. Joeng et al. reported that compounds $\mathbf{3}$, $\mathbf{8}$ and $\mathbf{1 0}$ were major components in Z. piperitum leaf, which had antioxidant activity and neuroprotective effect on $\mathrm{H}_{2} \mathrm{O}_{2}$-induced PC12 cell injury [24]. Compounds 4, 5 and $\mathbf{6}$ are quercetin glycosides, while compounds $\mathbf{7}$ and $\mathbf{9}$ belong to kaempferol derivatives. The antioxidant capacity of these five flavonoid glycosides were well elucidated in the literature [34]. Quercetin and other flavonol-type flavonoids in the aglycon form have been reported to show cytoprotective effect on linoleic acid hydroperoxide-dependent cytotoxicity in PC12 cells [35]. Furthermore, the previous study has proved that the antioxidant activity and cytoprotective effect of these flavonoids were closely associated with their special structure, which contained a 3-hydroxyl group, the $O$ dihydroxyl (3',4'-di-OH) structure in the B-ring and a 2,3double bond combined with a 4-keto group in the C-ring [14]. Therefore, the antioxidant ability and cytoprotection effect of ZLE on PC12 cell death induced by $\mathrm{H}_{2} \mathrm{O}_{2}$ could be mostly attributed to its diversity and high content of flavoniod glycosides.

\section{Conclusion}

The leaves of $Z$. bungeanum, grown in Hanyuan region, Southwest of China, showed a strong ability to scavenge ABTS and DPPH radicals and exhibited cytoprotective effect against $\mathrm{H}_{2} \mathrm{O}_{2}$-induced oxidative damage in PC12 cells. Ten flavonoid glycosides were identified as isovitexin, vitexin, hyperoside, isoquercitrin, rutin, foeniculin, trifolin, quercitrin, astragalin and afzelin. This is the first report for the presence of vitexin, isovitexin, astragalin, trifolin and afzelin in $Z$. bungeanum. The results imply that the leaves of $Z$. bungeanum might be a potential source of natural antioxidants. However, further studies, including in vivo experiments, are required to investigate the molecular mechanism of antioxidant behavior of $Z$. bungeanum leaf extract and these flavonoids.

\section{Acknowledgements}

We are grateful to Prof. Isomaro Yamaguchi, Graduate School of Agricultural and Life Sciences/Faculty of Agriculture, The Univ. of Tokyo, for his helpful comments and suggestions. This work was supported by funds of science and technology plan project of Sichuan province (2012NZ0023), primary research start project for youth in Sichuan University (2012SCU11045), Sichuan Youth Sci-tech Fund (2012JQ0019) and National Nature Science Fundation of China for Youth (81102157).

\section{References}

[1] Li, S.Z., Compendium of Materia Medica. People's Med. Publishing House, Beijing, China, 1982, 202.

[2] Gong, Y., Huang, Y., Zhou, L., Shi, X., Guo, Z., Wang, M., and Jiang, W., "Chemical composition and antifungal activity of the fruit oil of Zanthoxylum bungeanum Maxim. (Rutaceae) from China”, J Essent Oil Res 21. 174-178. 2009.

[3] Zhu, R.X., Zhong, K., Zeng, W.C., He, X.Y., Gu, X.Q., Zhao, Z.F., and Gao, H., "Essential oil composition and antibacterial activity of Zanthoxylum bungeanum”. Afr J Microbiol Res 5. 4631-4637. 2011.

[4] Tezuka, Y., Irikawa, S., Kaneko, T., Banskota, A.H., Nagaoka, T., Xiong, Q., Hase, K., and Kadota, S., "Screening of Chinese herbal drug extracts for inhibitory activity on nitric oxide production and identification of an active compound of Zanthoxylum bungeanum". J Ethnopharmacol 77. 209-217. 2001.

[5] Artaria, C., Maramaldi, G., Bonfigli, A., Rigano, L., and Appendino, G., "Lifting properties of the alkamide fraction from the fruit husks of Zanthoxylum bungeanum”. Int J Cosmet Sci 33. 328-333. 2011.

[6] Wang, L., Wang, Z., Li, X., Zhang, H., Zhou, X., and Zhang, H., "Analysis of Volatile Compounds in the Pericarp of Zanthoxylum bungeanum Maxim. by Ultrasonic Nebulization Extraction Coupled with Headspace Single-Drop Microextraction and GCMS”. Chromatographia 71. 455-459. 2010.

[7] Yang, X., “Aroma constituents and alkylamides of red and green Huajiao (Zanthoxylum bungeanum and Zanthoxylum schinifolium)”. J Agr Food Chem 56. 1689-1696. 2008.

[8] Xiong, Q., Dawen, S., Yamamoto, H., and Mizuno, M., "Alkylamides from pericarps of Zanthoxylum bungeanum". Phytochemistry 46. 1123-1126. 1997.

[9] Xiong, Q., Shi, D., and Mizuno, M., "Flavonol glucosides in pericarps of Zanthoxylum bungeanum”. Phytochemistry 39. 723725. 1995.

[10] Valko, M., Leibfritz, D., Moncol, J., Cronin, M.T., Mazur, M., and Telser, J., "Free radicals and antioxidants in normal physiological functions and human disease”. The Int J Biochem Cell B 39. 44-84. 2007.

[11] Liu, R.H., and Finley, J., "Potential cell culture models for antioxidant research”. J Agr Food Chem 53. 4311-4314. 2005.

[12] Middleton, E., Kandaswami, C., and Theoharides, T.C., "The effects of plant flavonoids on mammalian cells: implications for inflammation, heart disease, and cancer”. Pharmacol Rev 52. 673751. 2000.

[13] Kim, S.M., Kang, K., Jho, E.H., Jung, Y.J., Nho, C.W., Um, B.H., and Pan, C.H., "Hepatoprotective Effect of Flavonoid Glycosides from Lespedeza cuneata against Oxidative Stress Induced by tertButyl Hyperoxide”. Phytother Res 25. 1011-1017. 2011.

[14] Wolfe, K.L., and Liu, R.H., "Structure-activity relationships of flavonoids in the cellular antioxidant activity assay". J Agr Food Chem 56. 8404-8411. 2008.

[15] Ružić, I., Škerget, M., Knez, Ž., and Runje, M., "Phenolic content and antioxidant potential of macerated white wines”. Eur Food Res Technol 233. 465-472. 2011.

[16] Woldegiorgis, A.Z., Abate, D., Haki, G.D., and Ziegler, G.R., "Antioxidant property of edible mushrooms collected from Ethiopia”. Food Chem 157. 30-36. 2014.

[17] Gao, H., Nishida, J., Saito, S., and Kawabata, J., "Inhibitory effects of 5, 6, 7-trihydroxyflavones on tyrosinase”. Molecules 12. 86-97. 2007.

[18] Ding, X., Tang, J., Cao, M., Guo, C., Zhang, X., Zhong, J., Zhang, J., Sun, Q., Feng, S., and Yang, Z., "Structure elucidation and antioxidant activity of a novel polysaccharide isolated from Tricholoma matsutake”. Int J Biol Macromol 47. 271-275. 2010.

[19] Eckert, A., Steiner, B., Marques, C., Leutz, S., Romig, H., Haass, C., and Müller, W.E., "Elevated vulnerability to oxidative stressinduced cell death and activation of caspase-3 by the Swedish amyloid precursor protein mutation”. J Neurosci Res 64. 183-192. 2001.

[20] Barros, L., Dueñas, M., Dias, MI., Sousa, M.J., Santos-Buelga, C., and Ferreira, I.C., "Phenolic profiles of cultivated, in vitro cultured and commercial samples of Melissa officinalis L. infusions”. Food Chem 136. 1-8. 2013.

[21] Flores, G., Dastmalchi, K., Wu, S.B., Whalen, K., Dabo, A.J., Reynertson, K.A., Foronjy, R.F., D ' Armiento, J.M., and Kennelly, E.J., "Phenolic-rich extract from the Costa Rican guava (Psidium friedrichsthalianum) pulp with antioxidant and antiinflammatory activity. Potential for COPD therapy”. Food Chem 141. 889-895. 2013.

[22] Choi, Y., Jeong, H.S., and Lee, J., “Antioxidant activity of methanolic extracts from some grains consumed in Korea”. Food Chem 103. 130-138. 2007. 
[23] Markesbery, W.R., "Oxidative stress hypothesis in Alzheimer's disease”. Free Radic Biol Med 23. 134-147. 1997.

[24] Jeong, C.H., Kwak, J.H., Kim, J.H., Choi, G.N., Kim, D.O., and Heo, H.J., "Neuronal cell protective and antioxidant effects of phenolics obtained from Zanthoxylum piperitum leaf using in vitro model system”. Food Chem 125. 417-422. 2011.

[25] Zhang, J., Melton, L.D., Adaim, A., and Skinner, M.A. "Cytoprotective effects of polyphenolics on $\mathrm{H}_{2} \mathrm{O}_{2}$-induced cell death in SH-SY5Y cells in relation to their antioxidant activities". Eur Food Res Technol 228. 123-131. 2008.

[26] Jia, Y., Ji, L., Zhang, S., Xu, L., Yin, L., Li, L., Zhao, Y., and Peng, J., "Total flavonoids from Rosa Laevigata Michx fruit attenuates hydrogen peroxide induced injury in human umbilical vein endothelial cells”. Food Chem Toxicol 50. 3133-3141. 2012.

[27] Li, H., Cao, D., Yi, J., Cao, J., and Jiang, W., "Identification of the flavonoids in mungbean (Phaseolus radiatus L.) soup and their antioxidant activities”. Food Chem 135. 2942-2946. 2012.

[28] Lin, C.N., Kuo, S.H., Chung, M.I., Ko, F.N., and Teng, C.M., “A new flavone C-glycoside and antiplatelet and vasorelaxing flavones from Gentiana arisanensisi”. J Nat Prod 60. 851-853. 1997.

[29] Pereira, C.A.M., Yariwake, J.H., and McCullagh, M., "Distinction of the $C$-glycosylflavone isomer pairs orientin/isoorientin and vitexin/isovitexin using HPLC-MS exact mass measurement and in-source CID”. Phytochem Anal 16. 295-301. 2005.
[30] Guo, J., Xue, C., Shang, E., Duan, J., Tang, Y., and Qian, D., "Identification of hyperoside metabolites in rat using ultra performance liquid chromatography/quadrupole-time-of-flight mass spectrometry". J Chromatogr B 879. 1987-1992. 2011.

[31] Yang, L., Li, R., Tan, J., and Jiang, Z., "Polyphenolics Composition of the Leaves of Zanthoxylum bungeanum Maxim. Grown in Hebei, China, and Their Radical Scavenging Activities”. J Agr Food Chem 61. 1772-1778. 2013.

[32] Gómez-Alonso, S., Collins, V.J., Vauzour, D., Rodríguez-Mateos, A., Corona, G., and Spencer, J.P., "Inhibition of colon adenocarcinoma cell proliferation by flavonols is linked to a G2/M cell cycle block and reduction in cyclin D1 expression”. Food Chem 130. 493-500. 2012.

[33] Hollecker, L., Pinna, M., Filippino, G., Scrugli, S., Pinna, B., Argiolas, F., and Murru, M., "Simultaneous determination of polyphenolic compounds in red and white grapes grown in Sardinia by high performance liquid chromatography-electron spray ionisation-mass spectrometry”. J Chromatogr A 1216. 34023408. 2009.

[34] Heim, K.E., Tagliaferro, A.R., and Bobilya, D.J., "Flavonoid antioxidants: chemistry, metabolism and structure-activity relationships”. J Nutr Biochem 13. 572-584. 2002.

[35] Sasaki, N., Toda, T., Kaneko, T., Baba, N., and Matsuo, M., "Protective effects of flavonoids on the cytotoxicity of linoleic acid hydroperoxide toward rat pheochromocytoma PC12 cells". Chem Biol Interact 145. 101-116. 2003. 